\title{
Behavior of stable rhenium isotopes during magmatic processes and implications for the composition of the bulk silicate Earth
}

\author{
WENHAO WANG ${ }^{1}$, ALEX DICKSON ${ }^{1}$, JULIE PRYTULAK ${ }^{2}$, \\ PAUL S. SAVAGE ${ }^{3}$, EUAN NISBET ${ }^{1}$, MATHIEU \\ DELLINGER $^{2}$ AND ROBERT G HILTON ${ }^{2}$ \\ ${ }^{1}$ Royal Holloway, University of London \\ ${ }^{2}$ Durham University \\ ${ }^{3}$ University of St Andrews \\ Presenting Author: wenhao.wang@rhul.ac.uk
}

Rhenium (Re) is a redox sensitive element. Recent advances in the precision of measurement of the stable isotopic composition of Re allow exploration of its potential as a proxy for paleoredox and/or chemical weathering ${ }^{[1]}{ }^{[2]}$. However, a successful proxy must be grounded in a good understanding of the cycling of $\mathrm{Re}$ and Re isotopes in the solid Earth. Whilst Earth's core represents the main Re reservoir (230 ppb) and the abundance of Re in Bulk Silicate Earth was estimated to be $0.35 \mathrm{ppb}^{[3]}$, the effects of high-temperature processes such as partial melting and fractional crystalisation on the behavior of $\mathrm{Re}$ and stable $\mathrm{Re}$ isotope fractionation are currently unknown.

Here we present results of the analysis of Re concentration and Re isotopic $\left(\delta^{187} \mathrm{Re}\right)$ composition for two suites of whole rock samples, a well characterised differentiation sequence of lavas from Hekla volcano, Iceland ${ }^{[4]}$, and a $2.7 \mathrm{Ga}$ komatiite lave flow (Tony's flow) from the Belingwe greenstone belt, Zimbabwe ${ }^{[5]}$. The concentrations of Re of the Hekla lavas range between 0.02 to $1.4 \mathrm{ppb}$, and decrease from basalt to basaltic andesite, andesite, and dacite (46-69 wt.\% $\mathrm{SiO}_{2}$ ). The concentrations of Re of the Belingwe komatiites are between 0.3 and $0.9 \mathrm{ppb}^{[5]}$. Our new isotope data will provide insights into the fractionation of Re during magmatic differentiation and will provide the first constraints on the stable Re isotopic composition of the bulk silicate Earth.

[1] Dellinger et al. (2020) JAAS, 35, 377. [2] Dickson et al. (2020) GCA, 287, 221-228. [3] Walter et al. (2000) Siderophile elements, 265-289. [4] Savage et al. (2011) GCA, 75, 6124-6139. [5] Puchtel et al. (2009) GCA, 73, 6367-6389. 